\title{
Physical, Thermal Stability, and Mechanical Characteristics of New Bioplastic from Blends Cassava and Tannia Starches as Green Material
}

\author{
Marcelinus Christwardana ${ }^{*, 1}$, Ismojo², Sidik Marsudi ${ }^{1}$ \\ 'Department of Chemical Engineering, Institut Teknologi Indonesia, Jl. Raya Puspitek Serpong, South \\ Tangerang, Banten 15320, Indonesia. \\ ${ }^{2}$ Department of Automotive Mechanical Engineering, Institut Teknologi Indonesia, Jl. Raya Puspiptek Serpong, \\ South Tangerang, Banten 15320, Indonesia.
}

*Corresponding author E-mail: marcelinus@iti.ac.id; mchristwardana@gmail.com

Received June 22, 2020; Accepted December 10, 2020; Available online March 25, 2021

\begin{abstract}
This paper presents the study results of the morphology, physical properties, thermal stability, and mechanics of bioplastic blends made from tannia and cassava starch, with a varying weight from 0 to $95 \%$. The addition of tannia to the cassava starch-based bioplastic composition has the ability to reduce the number of pores, density, and water absorption with an average thickness of 0.21-0.29 mm. It also increased moisture content due to its nature, which is more hydrophilic than cassava starch. The result showed that the tensile strength of bioplastic ranged from $0.81-1.33 \mathrm{MPa}$ and elongated from $31-35 \%$. In addition, the thermal analysis data showed that the glass transition temperature shifted marginally due to intermolecular activity. This shows that tannia starch has promising potential as an alternative raw material for bioplastics to replace cassava starch which is more dominantly used as a food source.
\end{abstract}

Keywords: biomaterials; blend polymer; green materials; thin film; Xanthosoma undipes

\section{INTRODUCTION}

Plastic plays an essential role in every aspect of human life, due to its excellent thermal and mechanical properties, which makes them a stable and durable material (Soroudi \& Jakubowicz, 2013). Globally, the use of plastics significantly contributes to environmental pollution because it is indiscriminately disposed and not properly recycled. In addition, the degradation of synthetic plastic takes thousands of years; therefore, it remains in the environment for a long time. Every year, there are recorded deaths of animals due to their accidental consumption of plastic from their environment.

The shift in public opinion on plastics combined with the depletion of petroleum availability has encouraged the industry to look for alternative biodegradable materials (Ahmed et al., 2018). One such effort is the research on bioplastics, which are plastics made from renewable biomass sources. This product is naturally degraded in soil and relatively faster than petrochemical-based plastic (Bátori, Åkesson, Zamani, Taherzadeh, \& Horváth, 2018). Bioplastic is created to replace commercial plastic and reduce pollution. They are generally used for disposable items, such as packaging, bowls, straws, as well as mixtures for making bags, trays, containers, beverage bottles, and plastic pipes (Van de Velde \& Kiekens, 2002).
Starch, which is the main component in plants used to store energy, is the main ingredient in making bioplastics, and it is a biopolymer. According to Ratnayake \& Jackson (2008), starch is sourced from corn, potatoes, wheat and cassava, wheat, sorghum, rice, sago, arrowroot, and several other sources. It is also a significant contributor to the commercial food industry because of its unique thermal properties and functions (Castaño et al., 2017) Besides, starch has excellent potential as a source of various material applications, such as bioplastics.

The utilization of starch as bioplastics has been carried out since long ago. Van Soest, Hulleman, de Wit, \& Vliegenthart (1996) initially investigated the crystallinity of starch-based bioplastics, followed by Lörcks (1998) with research on the properties and applications of starch-based bioplastics. Gáspár et al. (2005) investigated water absorption in starch-based bioplastics, while Mose and Maranga (2011) reviewed the potential of nanocomposites as a starch-based bioplastic material. Although the use of starch in producing bioplastics has been in existence for a while, its use as the main ingredient is still lacking. For example, the starch material is widely used in the food industry; therefore, its use in bioplastics production raises competition. Besides, the properties of starchbased bioplastics also need to be improved for their use as plastic bags. 
However, the above-mentioned deficiencies are corrected with the use of blended materials such as Tannia, also known as Xanthosoma undipes, which is a plant that is a close relative of taro (Colocasia esculenta). Taro has the potential to be used as a substitute for making bioplastics due to its high starch content, which is up to $20 \%$ (Moorthy, Sajeev, \& Anish, 2018). Also, the utilization of tannia starch as a food ingredient is rarely compared to cassava or corn starch, thereby reducing the competition with usability.

In this study, the various weight of tannia starch was used in conjunction with cassava starch as a blend material for bioplastic. The tannia starch used in this experiment was derived from its tuber, which grows natively in Banten (Indonesia), and less utilized as food. Work involving tannia starch is very rarely done; moreover, the making of bioplastics based on tannia starch has never been done before. So, this has become our academic novelty. It is expected that the bioplastics produced have excellent physical properties and biodegradable, with the SEM technique used to observe its morphology, while the thickness, density, moisture content, and water absorption were calculated to determine its physical characteristic. The thermal stability of bioplastics was also investigated, while the mechanical characteristics were observed to recognize its strength.

\section{EXPERIMENTAL SECTION}

\section{Materials and MethodsMaterials}

Tannia flour was provided by KWT Bina Mandiri (Banten, Indonesia), and further processed to obtain the starch. The cassava was obtained from Dwilab Mandiri with $85.49 \%$ and $0.16 \%$ the dry mass of the starch and ash, respectively, with a $\mathrm{pH}$ of 6.1 and a moisture content of $12.35 \%$. Also, $98 \%$ of the Acetic acid (Technical Grade) was purchased from ROFA Laboratory Center, Bandung, Indonesia), while glycerol was purchased from Merck (New Jersey, USA).

\section{Tannia Starch Preparation}

Based on the analysis, starch content in the tannia flour is around $17 \%$. The tannia flour was washed and mixed with distilled water in a volume ratio of $1: 3$, blended for 5 minutes, and filtered using a cheesecloth. The above steps were repeated three times and allowed to stand for 24 hours, followed by the separation of the slurry into liquid (supernatant) and semi-solid starch (sediment). The supernatant was removed, while the semi-solid starch was obtained and dried at $25{ }^{\circ} \mathrm{C}$ (room temperature) before being stored in airtight plastic.

\section{Cassava-Tannia Starch-Based Bioplastic Preparation}

According to Table 1, approximately $10 \mathrm{~g}$ of starch and $60 \mathrm{~g}$ of distilled water was stirred in a beaker for 1 minute, with $5 \mathrm{~mL}$ of glycerol added to the mixture to increase the hydrophobicity of the film bioplastics. In addition, $5 \% \mathrm{v} / \mathrm{v}$ acetic acid was added to the mixture to hydrolyze the bonds in starch to form a polymer. The mixture is then heated at $80^{\circ} \mathrm{C}$ for 10 minutes, with the homogeneous components maintained. After gelatinization, the mixture is poured into a glass mold and dried at $30^{\circ} \mathrm{C}$ for seven days in an oven.

\section{Scanning Electron Microscopy}

SEM micrographs were obtained using a FieldEmission Scanning Electron Microscope (FE-SEM) and FEI Inspect F50 (Oregon, USA) to observe the morphology of the bioplastic surface. The sample was prepared by attaching bioplastic on a two-sided conductive adhesive tape and coated with carbon to make it more conductive (Fabra et al., 2018). SEM images are captured at different magnifications to ensure a clear bioplastic surface image.

\section{Thickness}

Digital calliper KRISBOW KW06-351 obtained from Jakarta, Indonesia, was used to measure bioplastic thickness (size $2 \mathrm{~cm} \times 2 \mathrm{~cm}$ ) in 15 different places, with the average calculated using the following formula (1):

average thickness $=\frac{\text { sum of measured thikness value }}{15}$

Density

Density from bioplastics is obtained using the following equation (2) (Salgado, Ortiz, Petruccelli, \& Mauri, 2010):

density $=\frac{M}{A \times D}$

where the density is in $\mathrm{g} / \mathrm{cm}^{3}, M$ is the mass $(\mathrm{g}), A$ is the area of the sample $\left(\mathrm{cm}^{2}\right)$, and $D$ is the thickness, with the analysis carried out in triple replication.

Table 1. Composition of Bioplastics

\begin{tabular}{lcccccc}
\hline Material & $0 \%$ & $5 \%$ & $10 \%$ & $20 \%$ & $50 \%$ & $95 \%$ \\
\hline Cassava starch $(\mathrm{g})$ & 10 & 9.5 & 9 & 8 & 5 & 0.5 \\
Tannia starch $(\mathrm{g})$ & 0 & 0.5 & 1 & 2 & 5 & 9.5 \\
Glycerol $(\mathrm{mL})$ & 5 & 5 & 5 & 5 & 5 & 5 \\
Acetic acid $5 \% \mathrm{v} / \mathrm{v}(\mathrm{mL})$ & 5 & 5 & 5 & 5 & 5 & 5 \\
Aquades $(\mathrm{mL})$ & 60 & 60 & 60 & 60 & 60 & 60 \\
\hline
\end{tabular}




\section{Moisture Content}

Precisely, bioplastic samples with a size of $2 \mathrm{~cm} \times$ $2 \mathrm{~cm}$ were weighed before being dried in an oven at $105{ }^{\circ} \mathrm{C}$ for 3 hours. The sample was then placed in a desiccator for the until it reaches room temperature, with the weight of the bioplastic re-measured. This analysis was carried out in triplicate, and the bioplastic moisture content is determined using equation (3) as follows:

moisture content $(\%)=\frac{W_{1}-W_{2}}{W_{1}} \times 100 \%$

where $W_{1}$ is the initial weight bioplastic, and $W_{2}$ is the final weight after drying.

\section{Water Absorption}

The dry weight of bioplastics $\left(\mathrm{W}_{0}\right)$ was determined after drying for 3 hours at $105^{\circ} \mathrm{C}$ in the oven and was immersed in deionized water for 24 hours (Salgado, Ortiz, Petruccelli, \& Mauri, 2010). To determine the absorption of water by bioplastics, after being soaked, the surface samples were cleaned from with a tissue before weighing $\left(W_{t}\right)$. Water absorption is determined using equation (4), and all analyses are carried out in triplicate as follows:

water absorption $(g)=W_{t}-W_{0}$

where $W_{0}$ is the initial weight of bioplastic, and $W_{+}$is the weight after immersion.

\section{TGA and DSC}

The thermal stability characteristics (TGA and DSC) of bioplastic samples were evaluated using STA-6000 from Perkin Elmer (Massachusetts, USA). The analysis was carried out in a nitrogen atmosphere at a flow rate of $10 \mathrm{ml} \cdot \mathrm{min}^{-1}$ to avoid the effects of oxidation. Samples of $10 \mathrm{mg}$ of bioplastics were crushed and stored in alumina containers, with the heating rate maintained at $10{ }^{\circ} \mathrm{C} \cdot \mathrm{min}^{-1}$ from 50 to $500{ }^{\circ} \mathrm{C}$ (Syafri et al., 2018).

\section{Mechanical Strength}

The mechanical strength of bioplastics comprising of tensile and elongation at break was determined according to the DIN 53504 tests on Rubber and Elastomer (Melgoza, Vallicrosa, Serenó, Ciurana, \& Rodríguez, 2014) by using Shimadzu AGS-X (Kyoto, Japan). The bioplastic was cut into a dogbone shape similar to the dumb-bells following type S3A, with specimens mounted in the extension grips of the machine and stretched at $200 \mathrm{~mm} \cdot \mathrm{min}^{-1}$. The test was carried out in five replicates.

\section{FTIR}

Shimadzu FTIR-8400s (Kyoto, Japan) was used to obtain the FTIR spectrum of bioplastic samples with a wavenumber region between $600 \mathrm{~cm}^{-1}$ and 4000 $\mathrm{cm}^{-1}$, using 32 accumulated scans and a spectral resolution of $4 \mathrm{~cm}^{-1}$.

\section{RESULTS AND DISCUSSION Morphology of Bioplastic}

Bioplastic microstructure analysis provides relevant information on the homogeneity and compatibility of its constituent components, which have a tremendous impact on bioplastic properties. The bioplastic surfaces of a mixture of cassava and tannia starch are shown in Figure la-f, while their photograph is displayed in Figure 1g. In some samples, white agglomerates appeared due to two possible phenomena. Firstly, there was a slight clumping of tannia in the cassava starch matrix and glycerol due to the gelatinization process. Secondly, it was due to the presence of a little amount of tannia flour when preparing the starch. Visually, some lumps were found on the bioplastics from cassava starch (Figure 1a), has a large number of pores, small in size, and also show a neat polymer surface. The addition of tannia starch as a substitute material decreases the number of pores, with an increase in size, according to Figure $1 \mathrm{~b}-\mathrm{f}$.
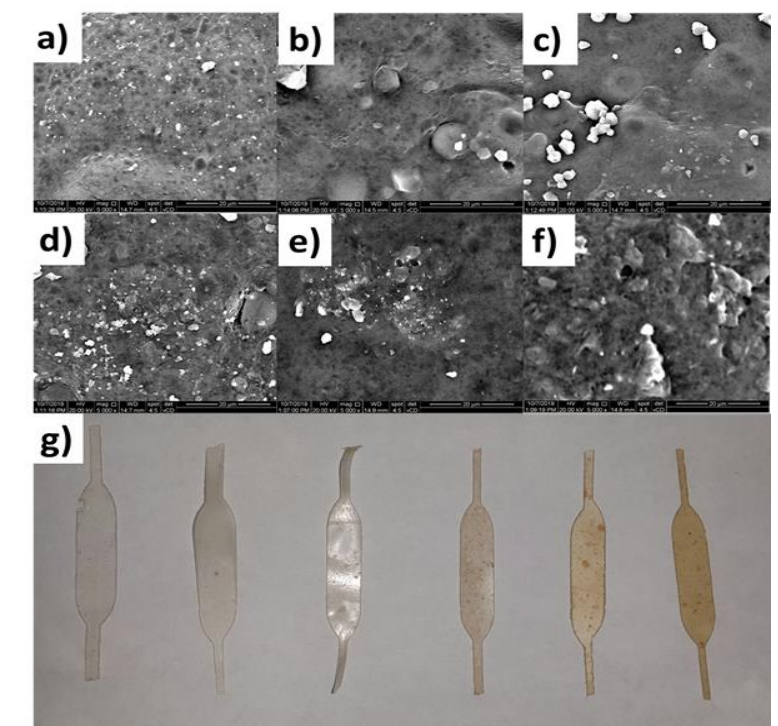

Figure 1. SEM images of cassava starch-based bioplastic with substitution of tannia starch a) $0 \%, b) 5 \%$, c) $10 \%$, d) $20 \%$, e) $50 \%$, and f) $95 \%$ by weight, while g) their photograph respectively (from left to right side). 


\section{Thickness}

Thickness is one of the important parameters because it is closely related to the calculation of other parameters such as mechanical strength, opacity, density, rate of gas transmission, and water vapor permeability (Sachdeva, Vashist, Chopra, \& Puri, 2017). The average bioplastic thickness was calculated from 15 different points using a digital calliper, which ranges between $0.21 \pm 0.05$ to 0.29 $\pm 0.01 \mathrm{~mm}$, as shown in Figure 2. These results indicate that bioplastic thickness is not significantly different; however, an increase in tannia starch in the composition has the ability to reduce its thickness. The decrease in bioplastic thickness is related to morphology, where the dominance of starch tannia increases pores. This is because the larger size of pores released many bubbles trapped in bioplastics, leaving free space, which decreases the thickness. Besides, tannia starch was not completely hydrolysed compared to cassava starch, thereby causing an imperfect gelatinization process with a low thickness.

\section{Density}

Figure 3 showed an initial decrease in the bioplastic density, which was followed by an increase. Bioplastic with cassava starch has the highest density of $0.098 \pm 0.017 \mathrm{~g} / \mathrm{cm}^{3}$, while substitution with $20 \%$ wt. of tannia reduced it to $0.071 \pm 0.020 \mathrm{~g} / \mathrm{cm}^{3}$. An increase in density was also shown when the amount of tannia starch in the composition was dominant by $95 \%$ wt. and its density reached $0.095 \pm 0.010 \mathrm{~g} / \mathrm{cm}^{3}$. The turning point was obtained when tannia had a portion of $40 \%$ wt. in the bioplastic composition. The hydrophilic nature, hardness, and granule of each starch are closely related to this phenomenon. As earlier explained, the empty space left by the bubble led to a decrease in bioplastic density along with the dominance of tannia in its composition. An increase and decrease in bioplastic density have the ability to affect its thickness, which was also often related to the molecular weight of components incorporated in bioplastics. In certain cases, plasticizers are responsible for decreasing its density (Razavi, Amini, \& Zahedi, 2015).

\section{Moisture Content}

The moisture content of cassava starch with the various weight of tannia is shown in Figure 4. Also, the bioplastics made from cassava starch had a moisture content of about $24.07 \pm 1.6 \%$, which increased with the substitution of tannia in its composition. The moisture content of cassava starch-based bioplastic with substitution of $5,10,20,50$, and $95 \%$ wt. tannia starch was $34.7 \pm 4.76,38.33 \pm 4.41,38.57 \pm$ $10.3,40.6 \pm 1.85$, and $43 \pm 3.08 \%$, respectively. This shows that tannia starch is more hydrophilic than cassava. The carbonyl content in hydrolyzed starch is also very influential in the hydrophilicity of bioplastics. Therefore, tannia starch is able to absorb water because it is more hydrophilic easily. Consequently, the more tannia starch used in bioplastic compositions, the higher the water content, while large pores cause water vapor to escape, With the opposite in cassava starch easily. According to Abral et al. (2018), the homogeneity of bioplastic components in the mixture aids in the diffusion of water molecules into the matrix, and in certain cases, a high amount of plasticization indirectly increases its water content.

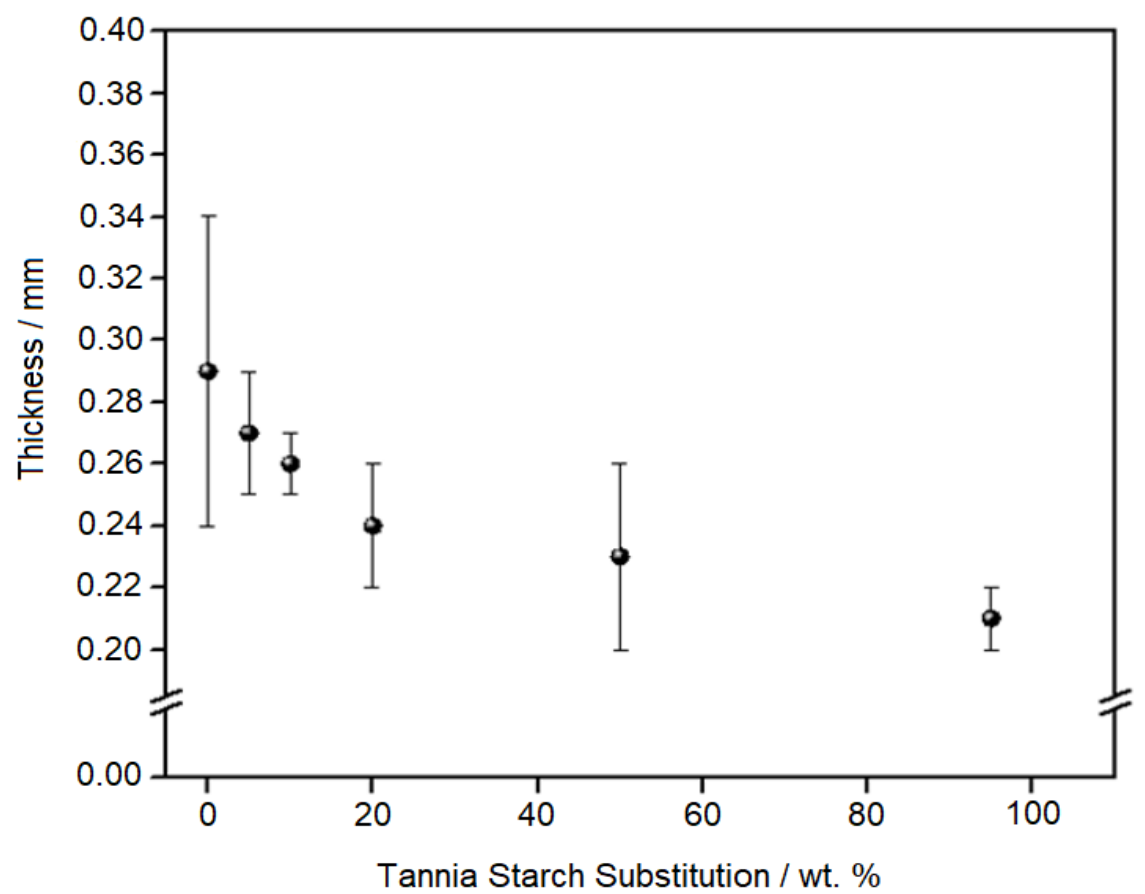

Figure 2. The thickness of cassava starch-based bioplastic with various substitution weight of tannia starch 


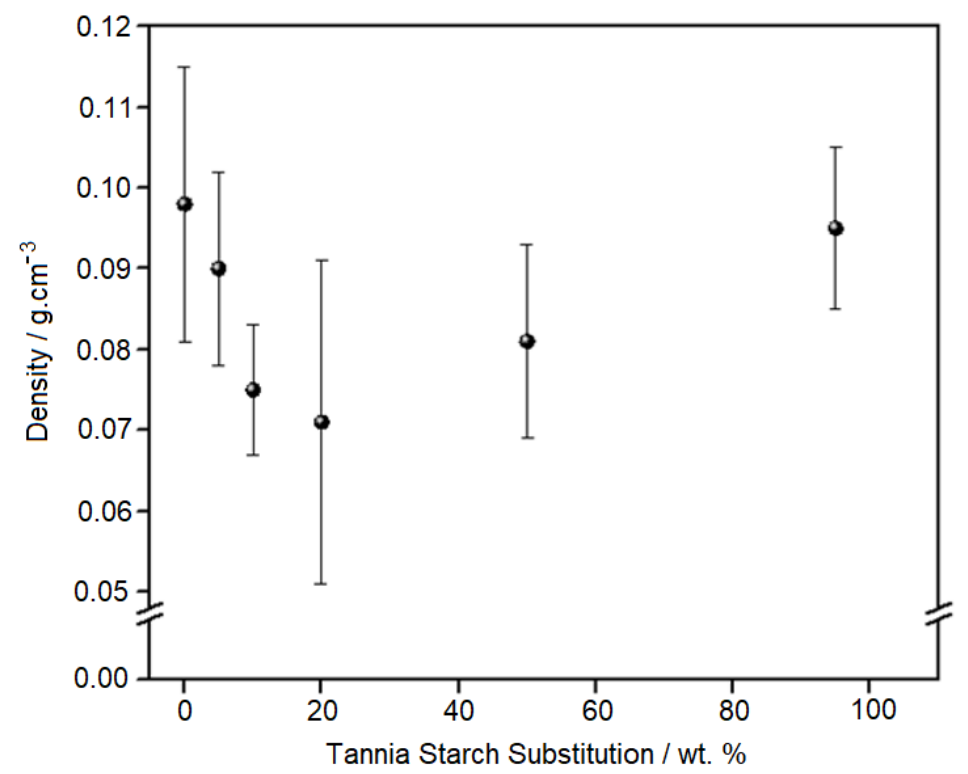

Figure 3. The density of cassava starch-based bioplastic with various substitution weight of tannia starch

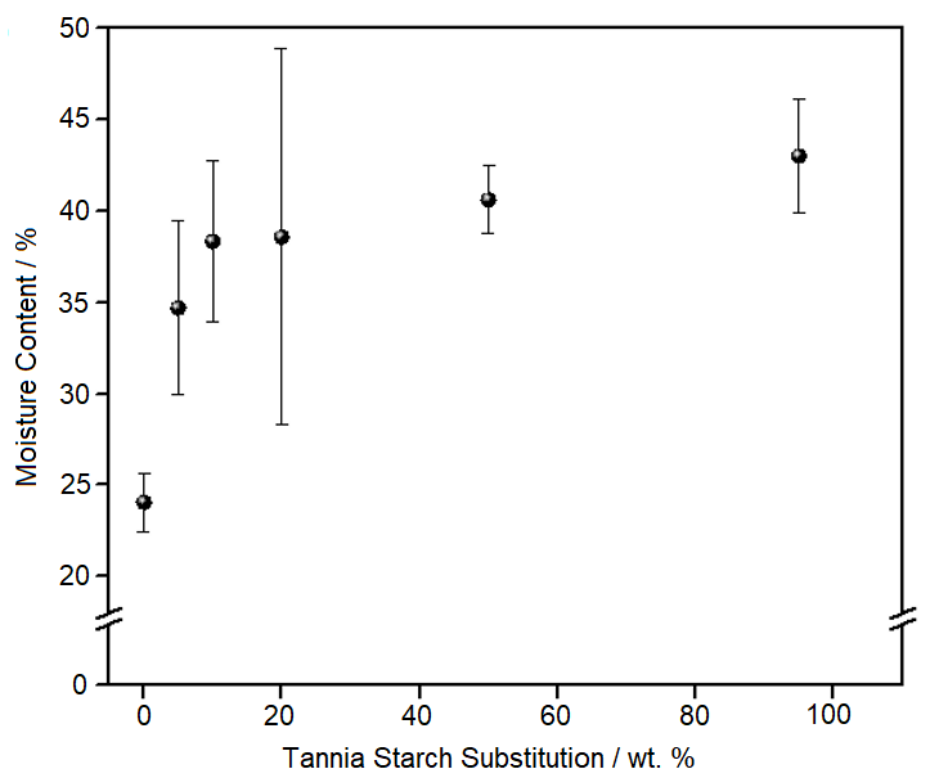

Figure 4. The moisture content of cassava starch-based bioplastic with various substitution weight of tannia starch

\section{Water Absorption}

Figure 5 shows the water absorption of cassava starch-based bioplastic with variations in the weight of tannia as substitution material. Bioplastics without tannia had the highest water absorption rate of 0.26 $\pm 0.03 \mathrm{~g}$. Tannia starch substitution of $5,10,20,50$, and $95 \%$ wt. in the bioplastic composition reduced the ability of water absorption to $0.23 \pm 0.05,0.20 \pm$ $0.02,0.17 \pm 0.02,0.15 \pm 0.01$, and $0.13 \pm 0.06 \mathrm{~g}$, respectively. Theoretically, an increase in tannia substitution in the bioplastic leads to a rise in water absorption. The results showed that the hydrophilic nature of starch does not affect this phenomenon. Pores size and quantity plays a more important role in this water absorption phenomenon. Based on SEM results, bioplastics which were dominated by cassava starch has a relatively higher number of pores than tannia, despite being smaller in size. This causes water to easily enter the bioplastic dominated by cassava starch, although it possessed less hydrophilic properties than tannia. The presence of flour residuals that are dominated by starch contributes to water absorption, where the residuals filled the pores in the matrix to prevent bioplastic from entering the water. Additionally, the decreased water absorption capacity is also associated with the hydrophobic nature of the plasticizer added to the manufacturing mixture (Sanyang, Sapuan, Jawaid, Ishak, \& Sahari, 2016). 


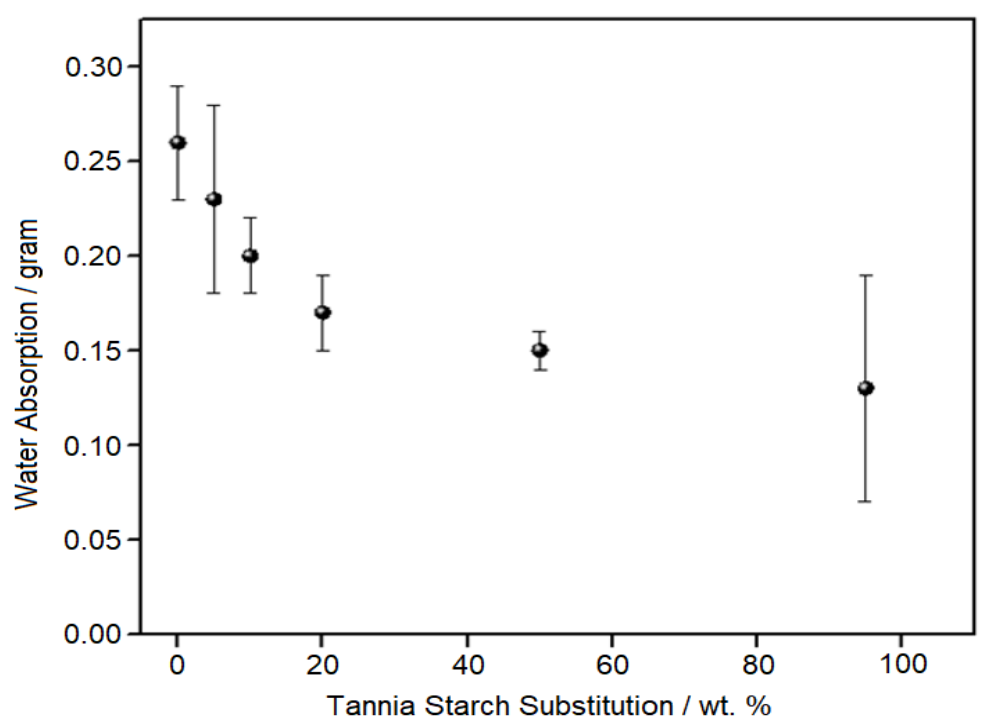

Figure 5. Water Absorption of cassava starch-based bioplastic with various substitution weight of tannia starch

\section{TGA and DSC Analysis}

The thermogravimetric analysis of bioplastic from cassava and tannia starch blend is shown in Figure 6a. In general, thermal degradation consists of three stages, with the first divided into two parts, thereby leading to a total of four. In the first stage, bioplastics lose their mass below the temperature of $105{ }^{\circ} \mathrm{C}$ by $10 \%$, which is associated with water loss due to the evaporation process as initially observed by Fakhouri et al. (2013). While in the second stage, the mass loss was approximately $5 \%$ at temperatures of 106 to 170 ${ }^{\circ} \mathrm{C}$ due to the evaporation of glycerol as a plasticizer with the rest water. The third stage shows the thermal expansion of bioplastic material, which was characterized by the loss of sample weight up to $70 \%$ at a temperature range of 171 to $350{ }^{\circ} \mathrm{C}$. In the thermal condensation process of the starch chain hydroxyl groups, ethers and unsaturated structures are formed as a process of starch depolymerization. In the fourth stage $\left(351-500^{\circ} \mathrm{C}\right)$, the reduction in bioplastic mass stops and the residual disintegration from oxidative atmospheric processes.

In Figure 7, the bioplastics dominated by tannia starch possess better thermal stability than those dominated by cassava starch. This is related to the crystallinity of the starch component when the dissolved amylose molecules are evenly distributed in the matrix. According to Rindlav-Westling, Stading, \& Gatenholm (2002), crystallinity increases with rising the amylose fraction in starch therefore, tannia starch probably may have more crystalline forms compared to cassava. According to the explanation by Prachayawarakorn, Chaiwatyothin, Mueangta, \& Hanchana (2003), the increase in thermal stability is due to the presence of excellent adhesion between bioplastic components. Esterification of the - $\mathrm{OH}$ group also plays a crucial role in increasing stability due to the starch degradation mechanism destruction.
Figure $6 \mathrm{~b}$ presents the thermogram heat flow curve for bioplastics based on cassava starch and tannia substitution, with variations of $0,5,10,20,50$, and $95 \%$ wt. In these figures, some small peak appeared and were associated with glass transition, crystallization, and melting temperatures. The first peak that appeared in the range $70-72{ }^{\circ} \mathrm{C}$ was associated with the glass transition temperature $\left(T_{g}\right)$, with the increase due to the relatively high crystallinity value found in tannia starch. However, as the tannia substitution increased in the bioplastic composition, the $T_{g}$ value a little bit shifted from 70.03 to $72.38^{\circ} \mathrm{C}$. $\mathrm{T}_{\mathrm{g}}$ value shift is also caused by interactions between the constituent components of bioplastics, which are cassava starch, tannia, and glycerol. Also, the substitution of tannia to the bioplastic composition showed superimposed endothermic relaxation that extends the trailing edge of the glass, and this is usually found when polymers with higher amorphous phase are heated (Dörrstein et al., 2018). This proves that cassava is dominated by the amorphous form rather than the crystalline. Perdomo et al. (2009) explained that water has the ability to make starch plasticity at high moisture levels, resulting in a decrease in $T_{g}$. The crystallization temperature $\left(T_{c}\right)$ showed at range $205.57-271.68{ }^{\circ} \mathrm{C}$ since starch bioplastic has semi-crystal structure. The other peak point was found in the temperature range of 323.21 $365.92{ }^{\circ} \mathrm{C}$, which corresponds to the $\mathrm{T}_{\mathrm{m}}$ of starch bioplastics. The peak has been levied to melting of crystallized amylopectin and co-crystallized amylose (Amin, Chowdhury, \& Kowser, 2019). The melting point of the cassava starch bioplastic was also affected by the presence of tannia starch in the composition, and its values increased when the cassava starch was substituted with tannia starch. According to Arvanitoyannis, Psomiadou, Nakayama, Aiba, \& Yamamoto (1997), shifts in $T_{g}$ and $T_{m}$ indicate the level of interaction between glycerol and starch. 

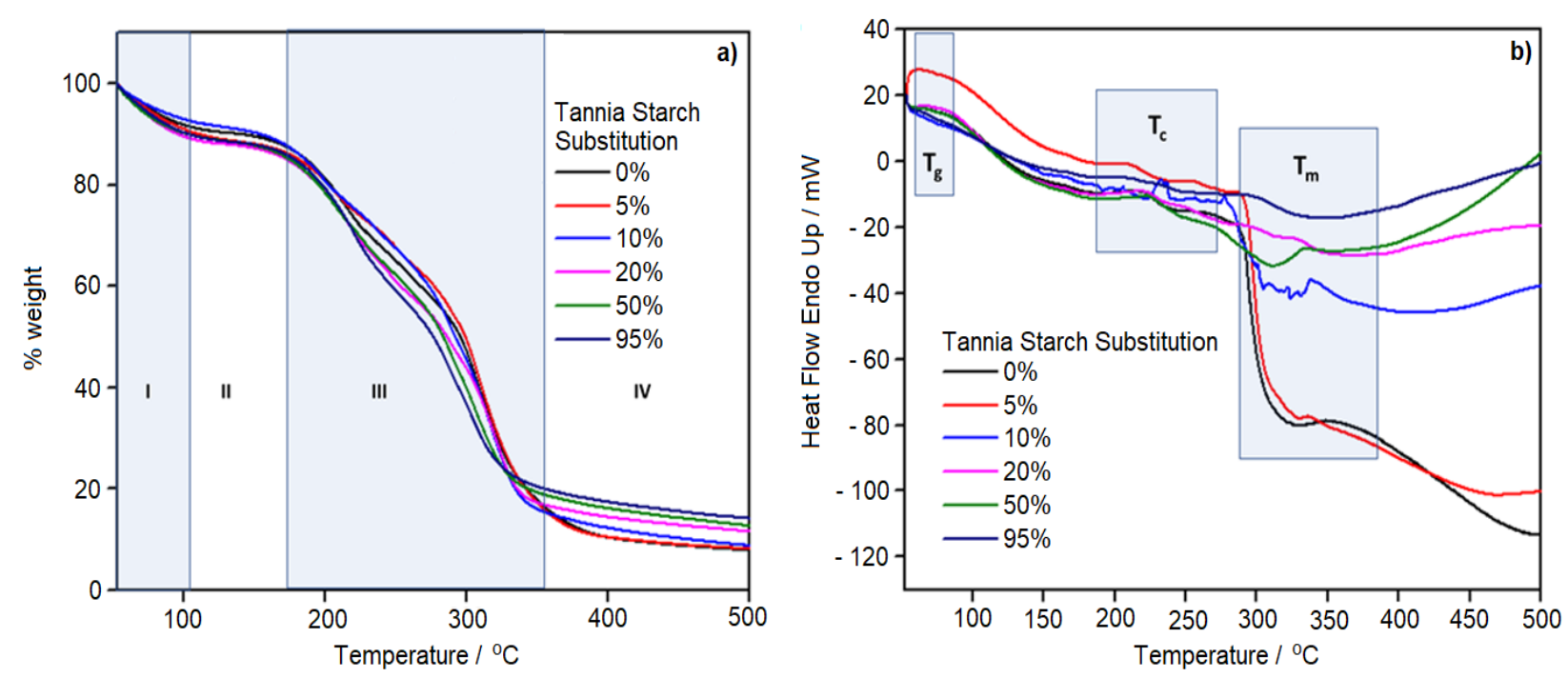

Figure 6. TGA thermogram (a) and DSC phase transition curves (b) of cassava starch-based bioplastic with various substitution weight of tannia starch

\section{Mechanical Strength}

The amorphous glass state of the material and the presence of crystalline greatly affected the mechanical response of bioplastics (Fabra et al., 2018). The substitution of tannia on cassava starchbased bioplastics was known to increase its tensile strength from $0.819 \pm 0.052$ to $1.325 \pm 0.067 \mathrm{MPa}$ (Figure 7). The presence of tannia caused an increase in the interaction of polymer chains in cassava starch and glycerol, which causes bioplastic hardness to be responsible for higher tensile strength. It is consistent with the thermal stability results in the previous section. Oluwasina, Olaleye, Olusegun, Oluwasina, \& Mohallem (2019) stated that the presence of higher starch content allowed for stronger polymer chain interactions leading to the cohesiveness of the film molecule, therefore, higher strength is needed to break down the tensile strength. However, the tensile strength does not change significantly when tannia was added to exceed $20 \%$ wt, although the intermolecular interactions and non-homogenous fraction were influenced (Mali, Grossmann, Garcia, Martino, \& Zaritzky, 2004; Abral et al., 2019). The bioplastics dominated by tannia starch had more crystalline phases leading to high tensile strength. Nevertheless, consequently, this reduced the interaction between the amorphous part of the amylose chain and amylopectin. The separation phases of the component and presence of starch micro-granules in the material matrix also have an essential effect on tensile strength (Podshivalov, Zakharova, Glazacheva, \& Uspenskaya, 2017). The robust interface tension between bioplastic components prevents the center of stress concentration from forming, thereby increasing tensile strength. In addition, the discontinuity in biopolymer networks, which may be due to weak interface tension, led to the loss of cohesion strength and mechanical resistance (Abral, Putra, Asrofi, Park, \& Kim, 2018). Besides the influence of intramolecular and intermolecular interactions, the homogeneity of starch dispersion affects the stability of the mechanical properties of the bioplastic. Syafri et al. (2018) stated that low tensile strength was also caused by the presence of many air bubbles trapped in the matrix.

Elongation at break is one of the critical parameters used to determine the use of bioplastics for packaging, carrier, or other purposes. The elongation expresses its flexibility and elasticity at the break, and this offers information on extending the length of a material to the breaking point (Pratiwi, Rahayu, \& Barliana, 2017). The elongation at break in this study is contrariwise proportional to the tensile strength, which decreased with an increase in weight of tannia as substitution material in the bioplastic composition (Versino, \& García, 2014). Elongation at break was reduced from $34.52 \pm 1.27$ to $31.08 \pm$ $1.09 \%$ due to the absence of plastic deformation in bioplastics, thereby exceeding the deformability. Moreover, since the crystalline phase of tannia starch is higher compared to cassava starch, the counterbalancing effect of the tannia starch causing an increase in the rigidity of the bioplastic (Oluwasina, Falola, Wahab, \& Idahagbon, 2018). As earlier explained, interactions between starch and glycerol molecules through hydrogen bonds led to extended chain lengths of bioplastic molecules, thereby increasing the elongation at break (Pratiwi et al., 2017). The hydrogen bonding occurs when glycerol diffuses properly in the hydrolyzed starch matrix. Therefore, the diffusivity and homogeneity of the bioplastic constituent components are also influential. 


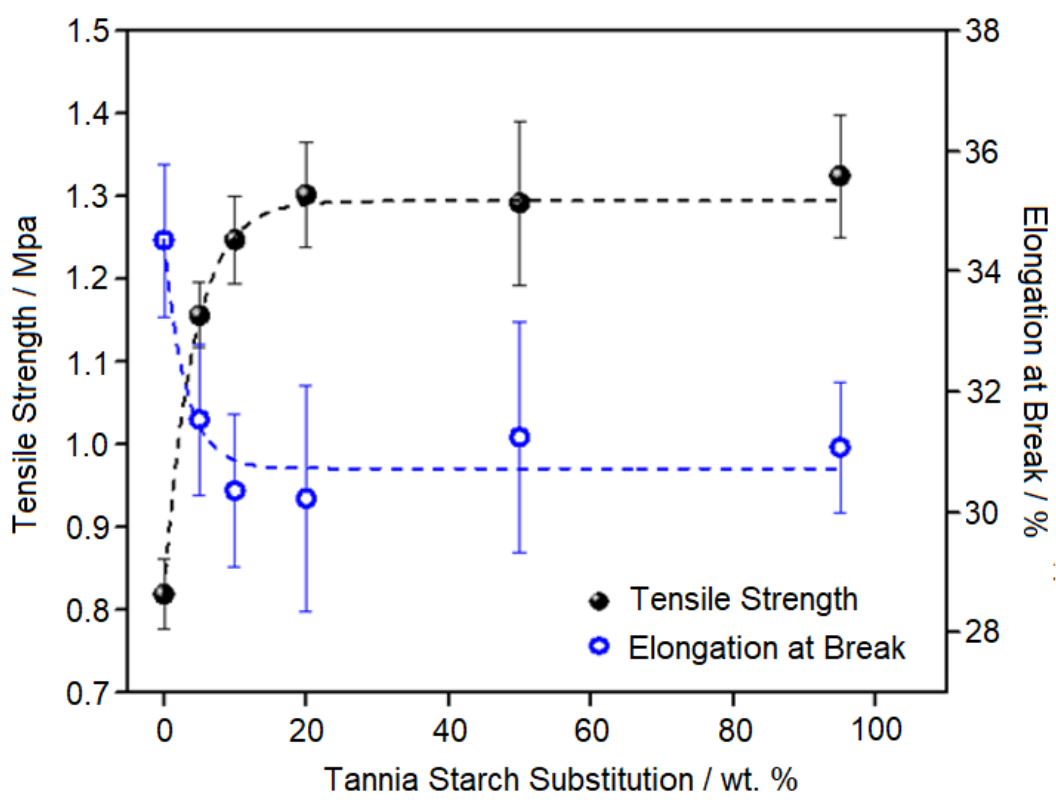

Figure 7. Tensile strength and elongation at break of cassava starch-based bioplastic with various substitution weight of tannia starch

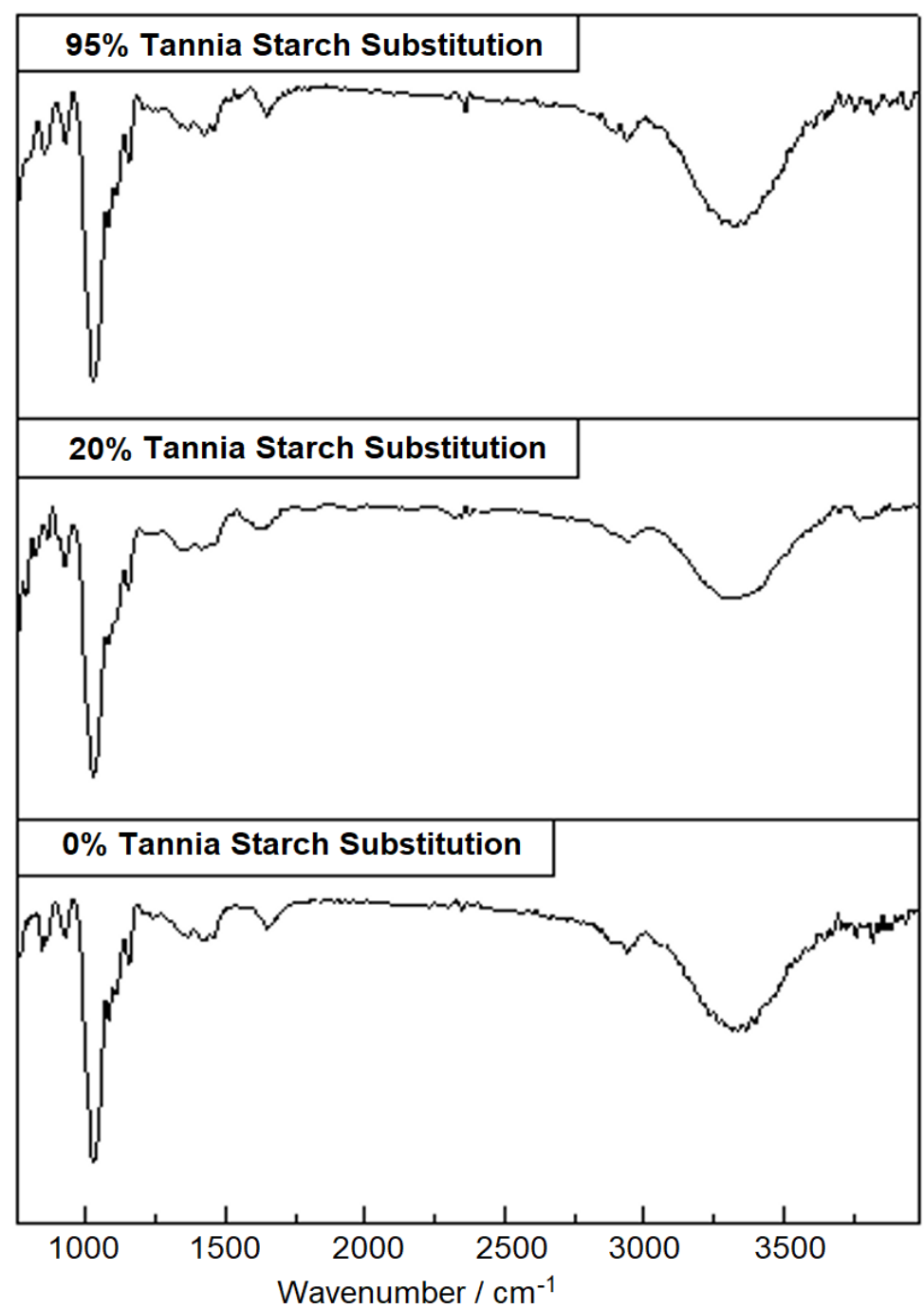

Figure 8. FTIR spectra of cassava starch-based bioplastic with 0,20 , and 95 wt. \% of substituted tannia starch. 


\section{FTIR Analysis}

FTIR analysis is needed to support the physical, thermal, and mechanical characteristics that have been analyzed previously. In this study, a substitution of 20 wt. \% tannia starch is optimal based on the analyzes described above. Figure 8 shows three samples on this FTIR characterization, namely 0, 20, and 95 wt. \% tannia starch as a substitute for bioplastics. The absorbance in the range $3200-3800$ $\mathrm{cm}^{-1}$ is the peak of the $\mathrm{O}-\mathrm{H}$ strain which is the structure of the starch. The $\mathrm{O}-\mathrm{H}$ strain also expressions that the hydrophilicity of starch is high (Sahari, Sapuan, Zainudin, \& Maleque, 2013), this affects the water and moisture absorption characteristics of the bioplastic. Meanwhile, the FTIR spectrum in the absorption bands at around 3400 and $2900 \mathrm{~cm}^{-1}$ was related to $\mathrm{O}-\mathrm{H}$ and $\mathrm{C}-\mathrm{H}$ stretched, respectively, shows that cassava starch and tannia starch as the basic ingredients for bioplastics. While cutting $\mathrm{O}-\mathrm{H}$ and bonding water molecules were seen in the absorption band around $1650 \mathrm{~cm}^{-1}$. The spectrum band $1500-1600 \mathrm{~cm}^{-1}$ was related to the distraction of water in starch (Himmelsbach, Khalili, \& Akin, 2002). The C-O stretch of C-O-C in the aryl-alkleter group lies in the absorbance band of around $1350 \mathrm{~cm}^{-1}$, and in the anhydroglucose ring it is detected on the FTIR spectrum of around $1020 \mathrm{~cm}^{-1}$ (Prachayawarakorn, Chaiwatyothin, Mueangta, \& Hanchana, 2013). Anhydroglucose stretching can be seen in the spectrum range $900-1030 \mathrm{~cm}^{-1}$ (Fang, Fowler, Tomkinson, \& Hill, 2002).

\section{CONCLUSIONS}

In conclusion, a bioplastic mixture of cassava starch was prepared with tannia by substituting the composition of cassava starch from 0 to $95 \%$ by weight. The morphology of bioplastics was examined by optical microscopy, and it was found that when the amount of cassava starch was substitution by tannia, it changed the surface from relatively smooth to rough. Besides, the number of pores was reduced; however, its size became large, which affected the thickness, density, moisture content, and water absorption during the gelatinization process.

The statistical analysis showed that the variations in the weight of tannia as a substitution agent of cassava starch-based bioplastic decreased the thickness by $24.14 \%$, density by $28.57 \%$, and water absorption by $50 \%$, with an increase in moisture content by $79.17 \%$. In addition to the presence of water vapor trapped in the bioplastic matrix, intramolecular and intermolecular bonds between bioplastic components also had a vital effect. The presence of tannia starch in the composition increased the tensile strength by $24 \%$ but decreased the elongation at the break by $22.41 \%$. Thermal analysis data showed the glass transition temperature shifted slightly by $2{ }^{\circ} \mathrm{C}$ due to intermolecular activity between the constituent components of bioplastics. From the overall analysis, it appears that 20 wt. \% substitution of tannia starch in the bioplastic composition is the most optimal one. Bioplastics based on tannia starch have great potential so that it is very interesting to research and develop for various purposes, for example packaging, carriers, or others, with characteristics that are close to or even better than petroleum-based plastics.

\section{ACKNOWLEDGEMENTS}

The authors would like to thank Institut Teknologi Indonesia for the financial support through "Hibah Internal ITI" (Grant No. 085/KP/LPKT-ITI/VI/2019). The authors also want to thank Decky Andrian and Tri Romana Putra for helping in data collection, and Dick Ferieno Firdaus from the University of Indonesia for supporting the mechanical analysis work.

\section{CONFLICT OF INTEREST}

The authors declare no conflict of interest.

\section{REFERENCES}

Abral, H., Dalimunthe, M. H., Hartono, J., Efendi, R. P., Asrofi, M., Sugiarti, E., \& Kim, H. J. (2018). Characterization of cassava starch biopolymer composites reinforced with micro scale water hyacinth fibers. Starch-Stärke, 70(7-8), 1700287.

Abral, H., Putra, G. J., Asrofi, M., Park, J. W., \& Kim, H. J. (2018). Effect of vibration duration of high ultrasound applied to bio-composite while gelatinized on its properties. Ultrasonics sonochemistry, 40, 697-702.

Abral, H., Soni Satria, R., Mahardika, M., Hafizulhaq, F., Affi, J., Asrofi, M., \& Muslimin, A. N. (2019). Comparative study of the physical and tensile properties of jicama (Pachyrhizus erosus) starch film prepared using three different methods. Starch-Stärke, 71(5-6), 1800224.

Ahmed, T., Shahid, M., Azeem, F., Rasul, I., Shah, A. A., Noman, M., \& Muhammad, S. (2018). Biodegradation of plastics: current scenario and future prospects for environmental safety. Environmental Science and Pollution Research, 25(8), 7287-7298.

Amin, M. R., Chowdhury, M. A., \& Kowser, M. A. (2019). Characterization and performance analysis of composite bioplastics synthesized using titanium dioxide nanoparticles with corn starch. Heliyon, 5(8), e02009.

Arvanitoyannis, I., Psomiadou, E., Nakayama, A., Aiba, S., \& Yamamoto, N. (1997). Edible films made from gelatin, soluble starch and polyols, Part 3. Food Chemistry, 60(4), 593-604.

Bátori, V., Åkesson, D., Zamani, A., Taherzadeh, M. J., \& Horváth, I. S. (2018). Anaerobic degradation of bioplastics: A review. Waste management, 80, 406-413.

Castano, J., Rodríguez-Llamazares, S., Sepúlveda, E., Giraldo, D., Bouza, R., \& Pozo, C. (2017). 
Morphological and structural changes of starch during processing by melt blending. StarchStärke, 69(9-10), 1600247.

Dörrstein, J., Scholz, R., Schwarz, D., Schieder, D., Sieber, V., Walther, F., \& Zollfrank, C. (2018). Effects of high-lignin-loading on thermal, mechanical, and morphological properties of bioplastic composites. Composite Structures, 189, 349-356.

Fabra, M. J., Martínez-Sanz, M., Gómez-Mascaraque, L. G., Gavara, R., \& López-Rubio, A. (2018). Structural and physicochemical characterization of thermoplastic corn starch films containing microalgae. Carbohydrate polymers, 186, 184191.

Fakhouri, F. M., Costa, D., Yamashita, F., Martelli, S. M., Jesus, R. C., Alganer, K., \& Innocentini-Mei, L. H. (2013). Comparative study of processing methods for starch/gelatin films. Carbohydrate polymers, 95(2), 681-689.

Fang, J. M., Fowler, P. A., Tomkinson, J., Hill, C. A. S. (2002) The preparation and characterisation of a series of chemically modified potato starches, Carbohydr. Polym. 47(3), 245-252.

Gaspar, M., Benkő, Z., Dogossy, G., Reczey, K., \& Czigany, T. (2005). Reducing water absorption in compostable starch-based plastics. Polymer Degradation and Stability, 90(3), 563-569.

Himmelsbach, D. S., Khalili, S., Akin, D. E. (2002) The use of FT-IR microspectroscopic mapping to study the effects of enzymatic retting of flax (Linum usitatissimum L) stems, J. Sci. Food Agric. 82(7), 685-696.

Lörcks, J. (1998). Properties and applications of compostable starch-based plastic material. Polymer degradation and stability, 59(1-3), 245-249.

Mali, S., Grossmann, M. V. E., García, M. A., Martino, M. N., \& Zaritzky, N. E. (2004). Barrier, mechanical and optical properties of plasticized yam starch films. Carbohydrate Polymers, 56(2), 129-135.

Melgoza, E. L., Vallicrosa, G., Serenó, L., Ciurana, J., \& Rodríguez, C. A. (2014). Rapid tooling using 3D printing system for manufacturing of customized tracheal stent. Rapid Prototyping Journal. 20, 2-12.

Moorthy, S. N., Sajeev, M. S., \& Anish, R. J. (2018). Functionality of Tuber Starches. In Starch in Food (pp. 421-508). Woodhead Publishing.

Mose, B. R., \& Maranga, S. M. (2011). A review on starch based nanocomposites for bioplastic materials. Journal of Materials Science and Engineering. B, 1(2B), 239.

Oluwasina, O. O., Falola, T., Wahab, O. J., \& Idahagbon, N. B. (2018). Enhancement of Physical and Mechanical Properties of Dioscorea Dumetorum Starch Films With
Dialdehyde Starch Solution. Starch-Stärke, 70(3-4), 1700148.

Oluwasina, O. O., Olaleye, F. K., Olusegun, S. J., Oluwasina, O. O., \& Mohallem, N. D. (2019). Influence of oxidized starch on physicomechanical, thermal properties, and atomic force micrographs of cassava starch bioplastic film. International journal of biological macromolecules, 135, 282-293.

Perdomo, J., Cova, A., Sandoval, A. J., García, L., Laredo, E., \& Müller, A. J. (2009). Glass transition temperatures and water sorption isotherms of cassava starch. Carbohydrate polymers, 76(2), 305-313.

Podshivalov, A., Zakharova, M., Glazacheva, E., \& Uspenskaya, M. (2017). Gelatin/potato starch edible biocomposite films: correlation between morphology and physical properties. Carbohydrate Polymers, 157, 1162-1172.

Prachayawarakorn, J., Chaiwatyothin, S., Mueangta, S., \& Hanchana, A. (2013). Effect of jute and kapok fibers on properties of thermoplastic cassava starch composites. Materials \& Design, 47, 309-315.

Pratiwi, R., Rahayu, D., \& Barliana, M. I. (2017). Characterization of Bioplastic from Rice Straw Cellulose. Research Journal of Pharmaceutical Biological and Chemical Sciences, 8, 217-221.

Ratnayake, W. S., \& Jackson, D. S. (2008). Starch gelatinization. Advances in food and nutrition research, 55, 221-268.

Razavi, S. M. A., Amini, A. M., \& Zahedi, Y. (2015). Characterisation of a new biodegradable edible film based on sage seed gum: Influence of plasticiser type and concentration. Food Hydrocolloids, 43, 290-298.

Rindlav-Westling, ^̊., Stading, M., \& Gatenholm, P. (2002). Crystallinity and morphology in films of starch, amylose and amylopectin blends. Biomacromolecules, 3(1), 84-91.

Sachdeva, A., Vashist, S., Chopra, R., \& Puri, D. (2017). Antimicrobial activity of active packaging film to prevent bread spoilage. International Journal of Food Science and Nutrition, 2, 29-37.

Sahari, J., Sapuan, S. M., Zainudin, E. S., Maleque, M. A. (2013) Mechanical and thermal properties of environmentally friendly composites derived from sugar palm tree, Mater. Des. 49, 285289.

Salgado, P. R., Ortiz, S. E. M., Petruccelli, S., \& Mauri, A. N. (2010). Biodegradable sunflower protein films naturally activated with antioxidant compounds. Food Hydrocolloids, 24(5), 525533.

Sanyang, M. L., Sapuan, S. M., Jawaid, M., Ishak, M. R., \& Sahari, J. (2016). Effect of plasticizer type and concentration on physical properties of biodegradable films based on sugar palm 
(Arenga pinnata) starch for food packaging. Journal of food science and technology, 53(1), 326-336.

Soroudi, A., \& Jakubowicz, I. (2013). Recycling of bioplastics, their blends and biocomposites: $\mathrm{A}$ review. European Polymer Journal, 49(10), 2839-2858.

Syafri, E., Kasim, A., Abral, H., Sulungbudi, G. T., Sanjay, M. R., \& Sari, N. H. (2018). Synthesis and characterization of cellulose nanofibers (CNF) ramie reinforced cassava starch hybrid composites. International journal of biological macromolecules, 120, 578-586.
Van de Velde, K., \& Kiekens, P. (2002). Biopolymers: overview of several properties and consequences on their applications. Polymer testing, 21 (4), 433-442.

Van Soest, J. J. G., Hulleman, S. H. D., de Wit, D., \& Vliegenthart, J. F. G. (1996) Crystallinity in starch bioplastics. Ind. Crops Prod. 5, 11- 22.

Versino, F., \& García, M. A. (2014). Cassava (Manihot esculenta) starch films reinforced with natural fibrous filler. Industrial Crops and Products, 58, 305-314. 